\title{
Systematic assessment of microneedle injection into the mouse cornea
}

\author{
Mario Matthaei ${ }^{1,2}$, Huan Meng ${ }^{1}$, Imran Bhutto ${ }^{1}$, Qingguo Xu ${ }^{1,3}$, Edwin Boelke ${ }^{4}$, Justin Hanes ${ }^{1,3}$ and Albert S Jun ${ }^{1 *}$
}

\begin{abstract}
Background: Corneal intrastromal injection is an important mode of gene-vector application to subepithelial layers. In a mouse model, this procedure is substantially complicated by the reduced corneal dimensions. Furthermore, it may be difficult to estimate the corneal area reached by the volume of a single injection. This study aimed to investigate intrastromal injections into the mouse cornea using different microneedles and to quantify the effect of injecting varying volumes. A reproducible injection technique is described.
\end{abstract}

Methods: Forty eyes of $20129 \mathrm{~Sv} / \mathrm{J}$ mice were tested. India ink was intrastromally injected using $30^{\circ}$ beveled $33 \mathrm{G}$ needles, tri-surface $25^{\circ}$ beveled $35 \mathrm{G}$ needles, or hand-pulled and $25^{\circ}$ beveled glass needles. Each eye received a single injection of a volume of 1 or $2 \mu \mathrm{L}$. Corneoscleral buttons were fixed and flat mounted for computer-assisted quantification of the affected corneal area. Histological assessment was performed to investigate the intrastromal location of the injected dye.

Results: A mean corneal area of $5.0 \pm 1.4 \mathrm{~mm}^{2}$ (mean \pm SD) and $7.7 \pm 1.4 \mathrm{~mm}^{2}$ was covered by intrastromal injections of 1 and $2 \mu \mathrm{L}$, respectively. The mean percentage of total corneal area reached ranged from 39\% to $53 \%$ for $1 \mu \mathrm{L}$ injections, and from 65\% to $81 \%$ for $2 \mu \mathrm{L}$ injections. Injections using the $33 \mathrm{G}$ needles tended to provide the highest distribution area. Perforation rates were $8 \%$ for $30^{\circ}$ beveled $33 \mathrm{G}$ needles and $44 \%$ for tri-surface beveled $35 \mathrm{G}$ needles. No perforation was observed with glass needle; however, intrastromal breakage of needle tips was noted in $25 \%$ of these cases.

Conclusions: Intracorneal injection using a $30^{\circ}$ beveled $33 \mathrm{G}$ needle was safe and effective. The use of tri-surface beveled $35 \mathrm{G}$ needles substantially increased the number of corneal perforations. Glass needles may break inside the corneal stroma. Injections of $1 \mu \mathrm{L}$ and $2 \mu \mathrm{L}$ resulted in an overall mean of $49 \%$ and $73 \%$ respectively of total corneal area involved.

Keywords: Cornea: gene therapy, Intrastromal injection

\section{Background}

Effective corneal gene therapy will require safe and effective gene delivery. However, lacrimation, mucus, blinking of the eyelid, and tight junctions of the corneal epithelium are a significant obstacle to genetic vectors $[1,2]$. Accordingly, intrastromal or intracameral injections are generally used for delivery of genetic therapeutics to subepithelial corneal layers [1].

Corneal thickness substantially varies among different animal species [3]. It is reported to be approximately

\footnotetext{
* Correspondence: aljun@jhmi.edu

${ }^{1}$ The Wilmer Eye Institute, Johns Hopkins Medical Institutions, $400 \mathrm{~N}$ Broadway, Baltimore, MD 21231, USA

Full list of author information is available at the end of the article
}

$354 \mu \mathrm{m}$ in rabbits and $170 \mu \mathrm{m}$ in rats, while it is only 89.2 to $123.8 \mu \mathrm{m}$ in mice $[3,4]$. Therefore, many studies in animals using corneal injections have used species other than mouse. However, the basic advantages of a mouse model are well-known: genetic models are often already available or easily practicable, experimental methods are usually better established, and expenses are comparably low. Thus, some studies describing the technique of intrastromal injections in mice have been conducted [5-17]. According to the method first described by Epstein and Stulting [9], most of these studies used a 33 gauge (G) needle with a bevel of $30^{\circ}$ or $45^{\circ}$ and the injected volume generally varied up to $2 \mu \mathrm{L}$ [5-7,9-13]. It is important to consider that this variation may cause 
differences in the corneal area reached by the injected fluid or therapeutic agent.

The major difficulties of injecting a mouse cornea are posed by its reduced thickness and the handling of a comparably large needle. Improved injection systems, like foot-pedal driven pumps and smaller gauged needles made of glass, are supposed to simplify the procedure but may cause problems like plugging or breakage of the needle tip, and they are more expensive than standard hand-held syringes $[8,15]$.

The present article describes a modified and reproducible injection method using hand-held syringes. In a systematic assessment, we compared injections into the mouse cornea by different types of microneedles and syringes and quantified the area reached by injections of different volumes.

\section{Methods}

\section{Animals}

$129 \mathrm{~Sv} / \mathrm{J}$ mice were bought from the Jackson Laboratory (The Jackson Laboratory, Bar Harbor, ME, USA). Animals ranged in age from 6 to 8 months. All procedures occurred according to the Association for Research in Vision and Ophthalmology statement for the Use of Animals in Ophthalmic and Vision Research.

\section{Needles and syringes}

Needles and syringes were obtained as follows (see Table 1 and Figure 1): 33 G needles (Hamilton, Reno, $\mathrm{NV}$, USA) were attached to a $2.5 \mu \mathrm{L}$ syringe (Hamilton); 35 G needles (WPI, Sarasota, FL, USA) were attached to a $10 \mu \mathrm{L}$ syringe (WPI); glass needles were hand-pulled from $1 \mathrm{~mm}$ diameter glass capillaries (WPI) and beveled to $25^{\circ}$ and an inner tip diameter of approximately $50 \mu \mathrm{m}$. Glass needles were attached to a $2.5 \mu \mathrm{L}$ syringe (Hamilton) by a dual ferrule adaptor (Hamilton).

\section{Injected solution}

Higgins Black India Ink (Chartpak, Leeds, MA. USA) was centrifuged for $10 \mathrm{~min}$ at $10,000 \mathrm{rpm}$. The supernatant was passed through a $0.2 \mu \mathrm{m}$ sterile filter (Corning, Corning, NY, USA) prior to injection.
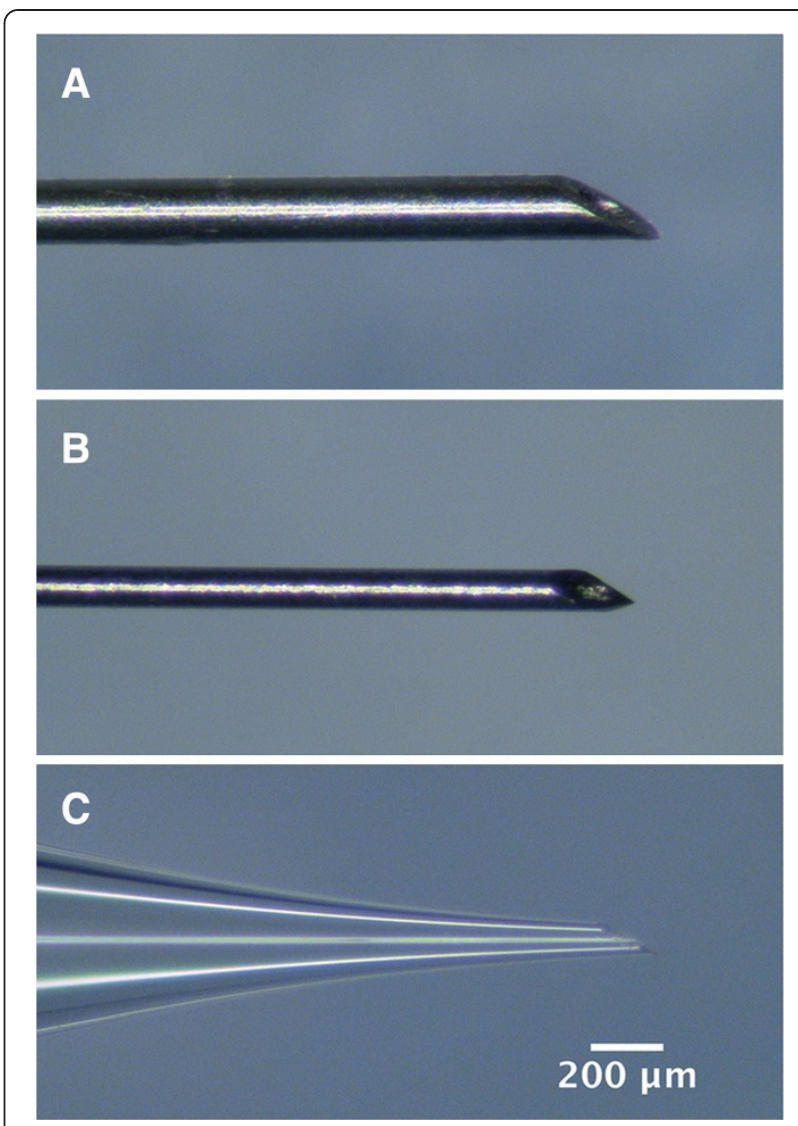

Figure 1 Needles used for intrastromal injections. (A) Hamilton $33 \mathrm{G} 30^{\circ}$ beveled, (B) WPI $35 \mathrm{G} 25^{\circ}$ tri-surface beveled, (C) WPI glass needle hand-pulled from $1 \mathrm{~mm}$ diameter glass capillary to an inner diameter of approximately $50 \mu \mathrm{m}$ and $25^{\circ}$ beveled.

\section{Intracorneal injection technique}

For anesthesia, a weight-adjusted combination of ketamine (100 mg/kg, Sigma-Aldrich, St. Louis, MO, USA), xylazine $(20 \mathrm{mg} / \mathrm{kg}$, Bioniche Pharma, Lake Forest, IL, USA) and acepromazine ( $3 \mathrm{mg} / \mathrm{kg}$, Sigma-Aldrich) was administered by intraperitoneal injection. Both eyes received an intracorneal injection of dye. All injections were performed by the same investigator (MM) after a period of 1 to 2 months of weekly training. Before each injection, proparacaine hydrochloride $0.5 \%$ eye drops

Table 1 Specification of microneedles used for intrastromal injections

\begin{tabular}{|c|c|c|c|c|c|}
\hline Needle type & Material & $\begin{array}{l}\text { Bevel } \\
\text { (degree) }\end{array}$ & $\begin{array}{l}\text { Nominal outer } \\
\text { diameter }(\mathrm{mm})\end{array}$ & $\begin{array}{l}\text { Nominal inner } \\
\text { diameter }(\mathrm{mm})\end{array}$ & $\begin{array}{l}\text { Total length } \\
(\mathrm{mm})\end{array}$ \\
\hline Hamilton, 33 G, point style 4 & $\begin{array}{l}\text { stainless } \\
\text { steel }\end{array}$ & 30 & 0.210 & 0.110 & 9.520 \\
\hline WPI, 35 G, tri-surface bevel & $\begin{array}{l}\text { stainless } \\
\text { steel }\end{array}$ & 25 & 0.135 & 0.055 & 35.000 \\
\hline $\begin{array}{l}\text { WPI, hand-pulled and } \\
\text { beveled glass needle }\end{array}$ & glass & 25 & $0.060^{\mathrm{a}}$ & $0.050^{\mathrm{a}}$ & $10.000^{\mathrm{a}}$ \\
\hline
\end{tabular}


(Bausch and Lomb, Madison, NJ, USA) and 0.5\% moxifloxacin eye drops (Vigamox; Alcon Laboratories, Fort Worth, TX, USA) were applied. All procedures occurred under a Nikon SMZ800 dissection microscope (Nikon, Melville, NY, USA). The anesthetized mouse was placed on a Styrofoam platform, and the head was stabilized using a thin strip of non-latex material fashioned from a disposable laboratory glove. The strip was thin enough not to occlude the nostrils of the mouse. A small hole was pre-cut into the strip to allow protrusion of the globe. The eye was cautiously proptosed by forceps retracting the upper and lower lid (Figure 2A). After fixation under the strip, the proptosis was maintained by tension along the margins of the pre-cut hole and the forceps were withdrawn. Care was taken that the strip did not strangle the central ocular blood vessels and optic nerve.

In the corneal mid-periphery, a small nick was made down to the anterior stroma with a $30 \mathrm{G}$ beveled needle (Becton Dickinson, Franklin Lakes, NJ, USA) (Figure 2B); the needle was slightly moved tangentially and upwards without withdrawal to confirm stromal placement. This created a small intrastromal pocket by separating the stromal lamellae, as could be observed by opacification of the anterior stroma (Figure 2B). A second smaller needle (see Table 1) was inserted into the pocket (Figure 2C). It was slowly tangentially pushed forward towards the corneal center until the tip of the needle had reached a position where approximately $0.5 \mathrm{~mm}$ of the needle shaft had entered the corneal stroma (Figure 2C). At this point, the India ink was forcefully injected without moving the needle tip (Figure 2D), and the needle subsequently was retracted. A perforation of the cornea
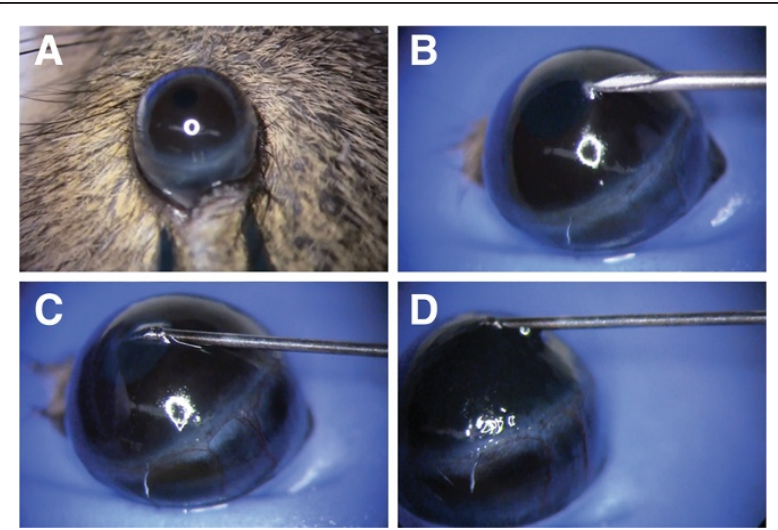

Figure 2 Intrastromal injection of a mouse cornea. (A) Proptosis of the eye by careful retraction of upper and lower lid with a forceps, (B) creation of a small intrastromal pocket in the mid-peripheral cornea using a $30 \mathrm{G}$ needle, (C) insertion of a smaller needle and intrastromal advancement towards the corneal center, (D) forceful injection of India ink was indicated by a sudden flattening of the anterior chamber, a temporary darkening of the aqueous humor by the ink, or leakage of clear aqueous humor from the injection site. All eyes with a corneal perforation were excluded for subsequent investigations from the study. Mice were euthanized 30 minutes after the injection, and both eyes were enucleated for further assessment, as described below.

\section{Quantitative analysis}

After enucleation, whole globes were fixed in 4\% paraformaldehyde in phosphate-buffered saline for $1 \mathrm{~h}$ at room temperature and the tissue was equilibrated in $20 \%$ sucrose solution at $4^{\circ} \mathrm{C}$ overnight. Subsequently, corneal buttons, including a narrow scleral rim, were excised. Four radial incisions were made and corneas were flat mounted on a glass slide. Pictures were taken at $5 \times$ magnification under the dissection microscope using a Canon VIXIA HFS21 digital camera (Canon, Lake Success, NY, USA). The injected corneal area could clearly be identified by a black staining of the tissue. The borders of the total corneal area were marked by Schwalbe's line. The injected area and total corneal area were measured using the ImageJ 1.43 software (National Institutes of Health, Bethesda, MD, USA).

\section{Histological evaluation}

Eight mouse eyes were processed for histological evaluation after intracorneal injection to assess the intrastromal location of the injected fluid. After enucleation, eyes were fixed as described above. Excised corneoscleral buttons were embedded in Tissue Tek OCT compound (Sakura Finetek, Torrance, CA, USA) at $-80^{\circ} \mathrm{C}$. Cryosections of $10 \mu \mathrm{m}$ were examined by hematoxylin-eosin staining.

\section{Statistics}

The stained areas of different groups were compared using the one-tailed Mann-Whitney nonparametric test. A $P$-value of $<0.05$ was regarded as statistically significant. Statistical software used included Excel 2008 for Mac (Microsoft, Redmond, WA, USA) and GraphPad Prism 4 (GraphPad, La Jolla, CA, USA).

\section{Results}

The mean total corneal endothelial surface was 10.52 $\pm 0.74 \mathrm{~mm}^{2}$. Examples of flat mounted murine corneas after 1 and $2 \mu \mathrm{L}$ injection using different needles are presented in Figure 3. Intracorneal injections of a volume of $1 \mu \mathrm{L}$ India ink resulted in a significantly $(P<0.05)$ smaller mean affected area $\left(5.0 \pm 1.4 \mathrm{~mm}^{2}\right)$ than injections of a volume of $2 \mu \mathrm{L}\left(7.7 \pm 1.4 \mathrm{~mm}^{2}\right)$. This difference was also significant $(P<0.05)$ for 1 and $2 \mu \mathrm{L}$ injections with each needle type. 

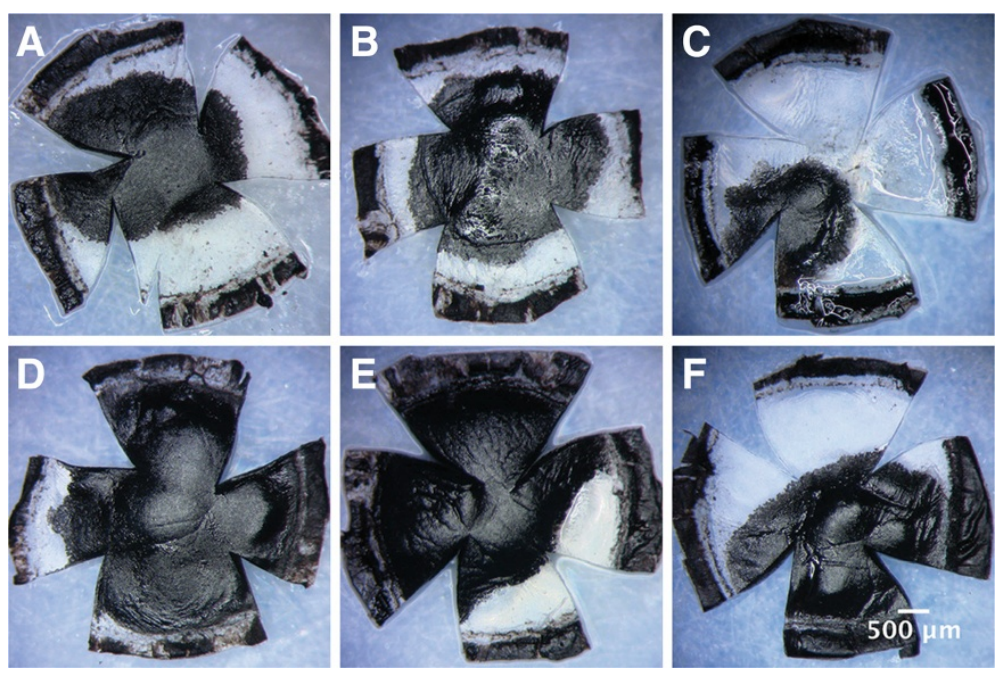

Figure 3 Flat mounts of $4 \%$ paraformaldehyde-fixed mouse corneas after intrastromal India ink injections. (A,B,C) Mouse corneas after injection of $1 \mu \mathrm{L}$ and $(\mathbf{D}, \mathbf{E}, \mathbf{F}) 2 \mu \mathrm{L}$ using a $33 \mathrm{G} 30^{\circ}$ beveled needle ( $A$ and $D$ ), a $35 \mathrm{G} 25^{\circ}$ tri-surface beveled needle (B and $E$ ) and a hand-pulled and beveled glass needle ( $C$ and $F)$.

Injections using a Hamilton $33 \mathrm{G}$ needle showed the tendency to affect the largest absolute dyed areas $(1 \mu \mathrm{L}$ : $\left.5.6 \pm 1.3 \mathrm{~mm}^{2}, 2 \mu \mathrm{L}: 8.6 \pm 1.6 \mathrm{~mm}^{2}\right)$, while injections with WPI 35 G needles $\left(1 \mu \mathrm{L}: 5.1 \pm 1.4 \mathrm{~mm}^{2}, 2 \mu \mathrm{L}: 7.3\right.$ $\left.\pm 0.8 \mathrm{~mm}^{2}\right)$ and glass needles $\left(1 \mu \mathrm{L}: 4.1 \pm 1.3 \mathrm{~mm}^{2}, 2 \mu \mathrm{L}\right.$ : $6.8 \pm 1.2 \mathrm{~mm}^{2}$ ) tended to provide smaller absolute affected areas (Figure 4). However, these differences between needles showed no statistical significance. The percentages of total corneal areas that were involved after a single injection of 1 or $2 \mu \mathrm{L}$ ink are displayed for each needle type in Table 2 . The mean proportionally affected corneal area was $49 \pm 14 \%$ for $1 \mu \mathrm{L}$ volume of injection and $73 \pm 15 \%$ for $2 \mu \mathrm{L}$ volume of injection, as displayed in Figure $5(P<0.05)$.

A perforation of the cornea occurred in one case (8\%) using $33 \mathrm{G}$ needles, in eight cases (44\%) using $35 \mathrm{G}$ needles, and in no case using hand-pulled glass needles.

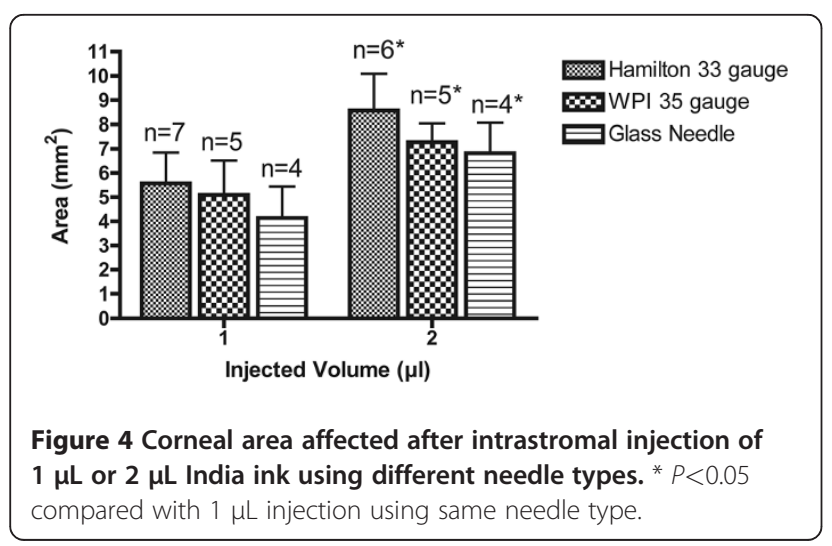

For the glass needles, a breakage of the tip occurred in two cases (25\%). A small amount of leakage was noted in all cases.

Histological assessment of injected corneas revealed a separation of the stromal lamellae and an interlamellar dispersion of the India ink in all cases, as can be seen in Figure 6.

\section{Discussion}

Due to its clarity, accessibility and clinical relevance, the cornea provides an excellent tissue for studies of gene transfer [18-20]. Gene delivery into subepithelial layers via topically-administered drops is hampered by tear flow, protective mucus layers, blinking and epithelial tight junctions. Intrastromal injection provides an important route to overcome these barriers. Despite the advantage of mouse models for corneal gene therapy studies, intrastromal injections in mice are difficult due to the small corneal thickness, and studies using intrastromal injections in the mouse cornea report corneal perforation rates up to $15 \%[9,15]$.

Table 2 Percentage of total corneal area affected after intrastromal injection of India ink

\begin{tabular}{lrrrrrrrrr}
\hline Needle type & \multicolumn{3}{c}{$\mathbf{1} \boldsymbol{\mu L}$ injection } & \multicolumn{3}{c}{$\mathbf{2} \boldsymbol{\mu L}$ injection } \\
\hline & $\begin{array}{c}\text { Percentage of total } \\
\text { area affected } \\
\text { (mean } \pm \text { SD) }\end{array}$ & $\begin{array}{c}\mathbf{n} \\
\text { Percentage of total } \\
\text { area affected } \\
\text { (mean } \pm \text { SD) }\end{array}$ & $\mathbf{n}$ \\
\hline Hamilton, 33 G & 53.28 & \pm & 12.37 & 7 & 80.63 & \pm & 14.28 & 6 \\
WPI, 35 G & 50.43 & \pm & 16.14 & 5 & 65.29 & \pm & 6.75 & 5 \\
WPI, glass needle & 38.67 & \pm & 9.03 & 4 & 69.65 & \pm & 19.09 & 4 \\
Total & 48.74 & \pm & 13.59 & 16 & 72.59 & \pm & 14.60 & 15 \\
\hline
\end{tabular}




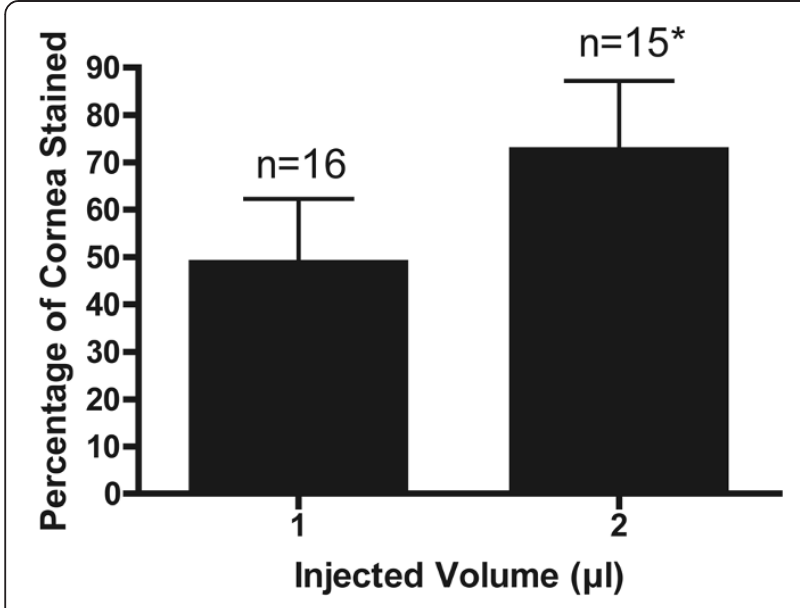

Figure 5 Percentage of corneal area affected after intrastromal injection of 1 or $2 \mu \mathrm{L}$ India ink. ${ }^{*} P<0.05$ compared with $1 \mu \mathrm{L}$ injection.

In mice, in contrast to humans, the corneal thickness increases towards the center [21]. This largely explains the method commonly used for intrastromal injection in mice, which involves a nick in the epithelium and anterior stroma made in the mid-periphery with a larger (30 to $32 \mathrm{G}$ ) needle. Subsequently, a finer needle is introduced and pushed forward, thereby separating the stromal fibers towards the center where the injection occurs. As described above in detail, we also applied this method but modified the mode of globe fixation.

The aim of this study was a systematic comparison of intrastromal injections using different microneedles in the mouse eye. Furthermore, our goal was to assess the corneal

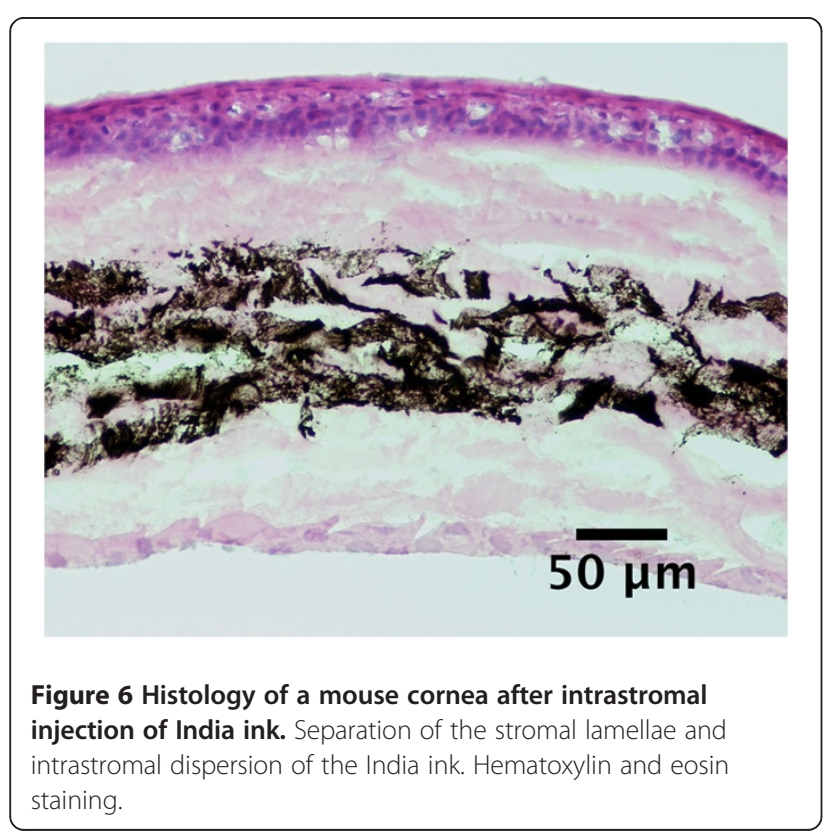

areas that may be affected by single injections of different volumes. Overall, the ratio between injected volume and the affected corneal area was reproducible. However, the ratio of injected volume and affected corneal area did not rise proportionally. This may have been caused by the leakage that was observed in all cases. The leakage is likely to rise with increasing volume of the injection, perhaps due to increased pressure inside the stroma. The volume of leakage was difficult to quantify, but appeared noticeably greater for the larger $(2 \mu \mathrm{L})$ injection volumes. Regardless, injected fluid was delivered to a large portion of the corneal surface area with $2 \mu \mathrm{L}$ injected volume.

There was a trend towards a reduced involved area with a decrease of the inner diameter of the microneedle. However, these results were not statistically significant.

The perforation rate of $8 \%$ that was achieved with the $33 \mathrm{G}$ needle is acceptable for practical use in most experimental studies. Using the tri-surface beveled $35 \mathrm{G}$ needle, a perforation rate as high as $44 \%$ was observed. This was most likely caused by the sharp tip of the trisurfaced bevel that did not give rise to a separation of the stromal fibers, but rather caused an easier penetration of the anterior chamber. The best results with regard to the rate of perforation were achieved using glass needles. However, in $25 \%$ of all cases, a breakage of the glass needle tip occurred inside the corneal stroma. This may cause additional tissue trauma in the postoperative course, which may be undesirable.

It was previously reported that a major drawback of hand-held syringes for injection of mouse eyes may be the difficulty of keeping the needle tip in the injection area while depressing the plunger [15]. According to our experience, this problem is mainly caused by ineffective eyefixation using forceps that are held with the non-injecting hand. The above-mentioned method of fixation with a strip of elastic material allowed for safe proptosis and fixation of the eye so that the injection could be administered more reliably. One disadvantage of this technique is the low risk of compression of the ophthalmic artery, vein or optic nerve, and care must be taken to avoid this complication by proper placement of the strip.

The use of a gas-powered or foot-pedal driven microinjection system may lead to a smoother course of the injection procedure and may, therefore, prevent the breakage of glass needle tips within the cornea. In this case, the use of hand-pulled glass needles could provide a safe and atraumatic method for intrastromal injections. When using hand-held syringes as in our study, however, the use of $33 \mathrm{G}$ metal needles provided the most reliable and effective outcomes.

\section{Conclusions}

Using the described technique intracorneal injection with a $30^{\circ}$ beveled $33 \mathrm{G}$ needle was safe and effective. The 
method presented here may be used as an easily reproducible guideline for intracorneal injections into the mouse cornea, and should facilitate use of mouse models for corneal gene therapy studies.

\section{Competing interests}

The authors declare that they have no competing interests.

\section{Authors' contributions}

MM designed the study, developed the injection technique, performed the injections and analyses, and prepared the manuscript; HM and QX participated in the performance of analyses, study design, and preparation of manuscript; IB participated in the development of the injection technique and preparation of the manuscript; EB and JH contributed to the study design and preparation of the manuscript; ASJ designed the study, developed the injection technique and prepared the manuscript. All authors read and approved the final manuscript.

\section{Acknowledgements}

The authors thank Professor Jerry Lutty, PhD, for technical assistance. This work was supported by a generous donation from the JG Foundation (ASJ and JH), and grants from the National Institutes of Health (KO8EY15523 and RO1EY19874 to ASJ), Research to Prevent Blindness (Career Development and Special Scholar Awards to ASJ), Wilmer Professors' Research Fund (ASJ), Wilmer Advisory Council Research Fund (ASJ), and the Medical IIIness Counseling Center (Chevy Chase, MD, USA to ASJ).

\section{Author details}

${ }^{1}$ The Wilmer Eye Institute, Johns Hopkins Medical Institutions, $400 \mathrm{~N}$ Broadway, Baltimore, MD 21231, USA. ²Department of Ophthalmology, University Medical Center Hamburg-Eppendorf, Martinistrasse 52, Hamburg 20246, Germany. ${ }^{3}$ The Center for Nanomedicine, Johns Hopkins University, 400 N Broadway, Baltimore, MD 21231, USA. ${ }^{4}$ Department of Radiology and Radiooncology, University Medical Center Duesseldorf, Moorenstrasse 5, Duesseldorf 40225, Germany.

Received: 18 November 2011 Accepted: 9 May 2012

Published: 20 June 2012

\section{References}

1. Klausner EA, Peer D, Chapman RL, Multack RF, Andurkar SV: Corneal gene therapy. J Control Release 2007, 124:107-133.

2. Hao J, Li SK, Kao WW, Liu CY: Gene delivery to cornea. Brain Res Bull 2010 81:256-261.

3. Reichard M, Hovakimyan M, Wree A, Meyer-Lindenberg A, Nolte I, Junghans C, Guthoff R, Stachs O: Comparative in vivo confocal microscopical study of the cornea anatomy of different laboratory animals. Curr Eye Res 2010, 35:1072-1080.

4. Lively GD, Jiang B, Hedberg-Buenz A, Chang B, Petersen GE, Wang K Kuehn $\mathrm{MH}$, Anderson MG: Genetic dependence of central corneal thickness among inbred strains of mice. Invest Ophthalmol Vis Sci 2010 51:160-171.

5. Moore JE, McMullen TC, Campbell IL, Rohan R, Kaji Y, Afshari NA, Usui T, Archer DB, Adamis AP: The inflammatory milieu associated with conjunctivalized cornea and its alteration with IL-1 RA gene therapy. Invest Ophthalmol Vis Sci 2002, 43:2905-2915.

6. Azkur AK, Kim B, Suvas S, Lee Y, Kumaraguru U, Rouse BT: Blocking mouse MMP-9 production in tumor cells and mouse cornea by short hairpin (sh) RNA encoding plasmids. Oligonucleotides 2005, 15:72-84.

7. Carlson EC, Liu CY, Yang X, Gregory M, Ksander B, Drazba J, Perez VL: In vivo gene delivery and visualization of corneal stromal cells using an adenoviral vector and keratocyte-specific promoter. Invest Ophthalmol Vis Sci 2004, 45:2194-2200.

8. Chintakuntlawar AV, Astley R, Chodosh J: Adenovirus type 37 keratitis in the C57BL/6J mouse. Invest Ophthalmol Vis Sci 2007, 48:781-788.

9. Epstein RJ, Stulting RD: Corneal neovascularization induced by stimulated lymphocytes in inbred mice. Invest Ophthalmol Vis Sci 1987, 28:1505-1513.

10. Jani PD, Singh N, Jenkins C, Raghava S, Mo Y, Amin S, Kompella UB, Ambati BK: Nanoparticles sustain expression of Flt intraceptors in the cornea and inhibit injury-induced corneal angiogenesis. Invest Ophthalmol Vis Sci 2007, 48:2030-2036.

11. Singh N, Amin S, Richter E, Rashid S, Scoglietti V, Jani PD, Wang J, Kaur R, Ambati J, Dong Z, Ambati BK: Flt-1 intraceptors inhibit hypoxia-induced VEGF expression in vitro and corneal neovascularization in vivo. Invest Ophthalmol Vis Sci 2005, 46:1647-1652.

12. Stechschulte SU, Joussen AM, von Recum HA, Poulaki V, Moromizato Y, Yuan J, D'Amato RJ, Kuo C, Adamis AP: Rapid ocular angiogenic control via naked DNA delivery to cornea. Invest Ophthalmol Vis Sci 2001, 42:1975-1979.

13. Zhang $\mathrm{H}$, Chen $\mathrm{H}$, Niu J, Wang $\mathrm{Y}$, Xie L: Role of adaptive immunity in the pathogenesis of Candida albicans keratitis. Invest Ophthalmol Vis Sci 2009 50:2653-2659.

14. Zhou R, Dean DA: Gene transfer of interleukin 10 to the murine cornea using electroporation. Exp Biol Med (Maywood) 2007, 232:362-369.

15. Hendricks RL, Epstein RJ, Viana MA, Hoffmann DA: A reproducible method for injecting the mouse corneal stroma. Invest Ophthalmol Vis Sci 1991, 32:366-370.

16. Blair-Parks $\mathrm{K}$, Weston $\mathrm{BC}$, Dean DA: High-level gene transfer to the cornea using electroporation. J Gene Med 2002, 4:92-100.

17. Galiacy SD, Fournie P, Massoudi D, Ancele E, Quintyn JC, Erraud A, Raymond-Letron I, Rolling F, Malecaze F: Matrix metalloproteinase 14 overexpression reduces corneal scarring. Gene Ther 2011, 18:462-468.

18. Williams KA, Coster DJ: Gene therapy for diseases of the cornea - a review. Clin Experiment Ophthalmol 2010, 38:93-103.

19. Mohan RR, Tovey JC, Sharma A, Tandon A: Gene therapy in the cornea: 2005-present. Prog Retin Eye Res 2012, 31:43-64

20. Kampik D, Ali RR, Larkin DF: Experimental gene transfer to the corneal endothelium. Exp Eye Res 2012, 95:54-59.

21. Henriksson JT, McDermott AM, Bergmanson JP: Dimensions and morphology of the cornea in three strains of mice. Invest Ophthalmol Vis Sci 2009, 50:3648-3654.

doi:10.1186/2047-783X-17-19

Cite this article as: Matthaei et al:: Systematic assessment of microneedle injection into the mouse cornea. European Journal of Medical Research 2012 17:19.

\section{Submit your next manuscript to BioMed Central and take full advantage of:}

- Convenient online submission

- Thorough peer review

- No space constraints or color figure charges

- Immediate publication on acceptance

- Inclusion in PubMed, CAS, Scopus and Google Scholar

- Research which is freely available for redistribution 